from: Roche, Pfizer, Speakers bureau: Roche, Merck Sharp \& Dohme, Abbott, Pfizer, S. Valieva Grant/research support from: Roche, Bristol-Myers Squibb, Speakers bureau: Roche, Merck Sharp \& Dohme, Bristol-Myers Squibb, Medac, Novartis, R. Denisova Grant/research support from: Roche, Centocor, Novartis, Speakers bureau: Roche, Merck Sharp \& Dohme, Abbott, Medac, O. Lomakina: None declared, K. Isaeva: None declared, E. Kashchenko Grant/research support from: Novartis, A. Karaseva: None declared DOI: 10.1136/annrheumdis-2017-eular.5944

\section{FRI0155 PREVALENCE OF HBV INFECTION AND RISK OF REACTIVATION ON BIOLOGIC TREATMENT: A POPULATION-BASED OBSERVATIONAL STUDY OF RHEUMATOID ARTHRITIS SUBJECTS IN A NORTHERN ITALY AREA}

M. Meroni ${ }^{1,2}$, L. Sangiovanni ${ }^{3}$, E. Lupi ${ }^{1}$, S. Fagiuoli ${ }^{3}$, M. Limonta ${ }^{1}$. ${ }^{1}$ Rheumatology Unit, ASST Papa Giovanni XXIII, Bergamo; ${ }^{2}$ Research Laboratory and Academic Division of Clinical Rheumatology, Internal Medicine Dept., University of Genova, Genova; ${ }^{3}$ Gastroenterology and Transplant Hepatology Unit, ASST Papa Giovanni XXIII, Bergamo, Italy

Background: The introduction of biologic agent's treatment in rheumatic diseases dramatically changed their outcome, but raised some concerns about infections recrudescence. Due to the prevalence of hepatitis B virus (HBV) among Italian general population (2-6\%), the possibility of a disease reactivation in case of an immunosuppressive treatment has to be considered.

Objectives: Aim of this prospective, population-based observational study was to assess the prevalence of HBV (both in chronic carriers and recativated) rheumatoid arthritis (RA) patients in our setting; to verify if these findings were in line to the Italian and European-reported data; finally, to evaluate the final outcome of HBV RA subjects.

Methods: We enrolled the totality of RA patients treated by biologics and, therefore, consulting our Unit at least every 12 weeks, from December 2015 to January 2017. According to the current (ACR/EULAR and AASLD) guidelines, every subject was screened for HBV before starting biologic treatment. Descriptive statistics was performed. Acute infection; previous (resolved) infection; inactive and active carrier; and vaccine-immunized subjects were defined according to Tab. I.

Results: A totality of 265 RA patients (female $56.3 \%$; male $43.7 \%$; mean age $36+/-20$ years) underwent biologic treatment after succeeding the screening ( $\mathrm{HBsAg}+$ subjects were excluded). The huge majority of them $(82 \%)$ was treated by TNF-alpha inhibitors (TNFi), since the remaining received biologic agents with different mechanisms of action. We overall detected $33(12.5 \%)$ inactive carriers, for whom HBsAg and HBV DNA periodical monitoring was suggested; in 3 of them $(1.1 \%$ of the study population), HBV DNA became detectable, with a low viral load $(<2000 \mathrm{UI} / \mathrm{ml})$ : they prosecute the biologic therapy after the introduction of the standard prophylaxis (lamivudine $100 \mathrm{mg}$ daily) and a more strictly (periodic liver enzymes and liver ETG evaluation) monitoring.

In occasion of the screening, we observed $6(2.3 \%) \mathrm{HBV}$-immunized (due to vaccine) and $6(2.3 \%)$ previously infected $(\mathrm{HBcAb}+)$ patients: for the first ones no action is required, since the latter were put on standard prophylaxis before undergoing biologic agent and monitored. One of them $(0.38 \%)$ developed, after 6 months of treatment, HBV reactivation with high-level (>2000 Ul/ml) detectable DNA and liver enzymes elevation (>normality $\times 3$ ). She was therefore stopped from receiving biologic agent and put on entecavir $1 \mathrm{mg}$ daily.

\section{Interpretation of HBV serologic test results}

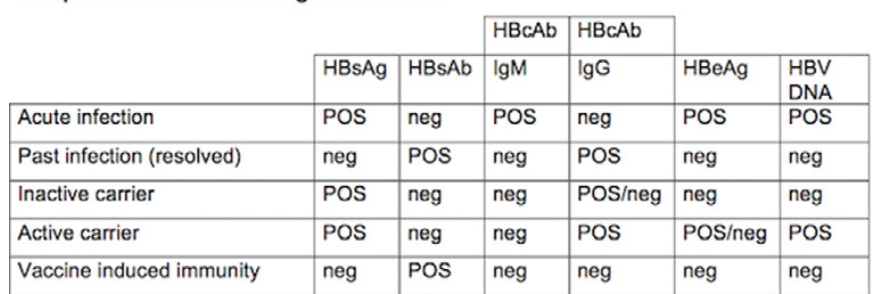

POS: positive; neg: negative; HBsAg: hepatitis B surface antigen; HBsAb: hepatitis B surface antibody;

HBcAb: hepatitis B core antibody; HBeAg: hepatitis B envelope antigen.

Conclusions: Our prospective, population-based observational study, performed in a first-level referring Hospital in a highly populated area, suggests some considerations. In a way, our data reported a significantly higher prevalence of HBV infection "contact" among our RA population, in comparison to the general one $(p<0.05)$. This issue has previously been reported and could be justified but the generally higher HBV diffusion in certain area (i.e., Italy); by the age/ethnicity of the sample; and, finally, by the bias consisting in an extensive screening of these patients. On the other hand, our experience suggests that a tight monitoring of parameters predicting infectious flare should lead to a prompt diagnosis and a lower number of complications for these peculiar patients, as observed in our population.

Disclosure of Interest: None declared

DOI: 10.1136/annrheumdis-2017-eular.2572

\section{FRI0156 DO CHANGES IN ADIPOCYTOKINES CORRELATE WITH CHANGES TO DISEASE ACTIVITY IN RHEUMATOID ARTHRITIS? FINDINGS FROM THE TOMORROW STUDY}

M. Tada ${ }^{1}$, K. Inui ${ }^{2}$, Y. Sugioka ${ }^{3}$, T. Okano $^{2}$, K. Mamoto $^{2}$, T. Koike $^{3}$, H. Nakamura ${ }^{2}$. ${ }^{1}$ Orthopaedic Surgery, Osaka City General Hospital, ${ }^{2}$ Orthopaedic Surgery; ${ }^{3}$ Center of Senile Degenerative Disorders, Osaka City University Graduate School of Medicine, Osaka, Japan

Background: Cytokines released from mast cells evoke inflammation and correlate with arteriosclerotic lesions and autoimmune disease ${ }^{1}$. The relationship between disease activity and lipid metabolism is a notable in research surrounding rheumatoid arthritis (RA). RA patients without disease control reportedly show high titers of leptin or adiponectin as adipocytokines ${ }^{2}$.

Objectives: We analyzed the interaction between changes in disease activity and adipocytokines using data from the TOMORROW (TOtal Management Of Risk factors in Rheumatoid arthritis patients to IOWer morbidity and mortality clinical trial) study, a 10-year prospective study (registration number, UMIN000003876). Methods: We analyzed data collected from the cohort of the TOMORROW study including 193 patients with RA and age- and sex-matched 194 healthy individuals (controls). We compared changes in leptin and adiponectin ( $\Delta$ leptin and $\Delta$ adiponectin) in both groups between baseline and after 3 years. Correlations with the change in disease activity ( $\triangle \mathrm{DAS} 28 \mathrm{ESR})$ during 3 years and changes in $\Delta$ leptin and $\triangle$ adiponectin in RA were investigated by univariate analysis.

Results: Leptin levels increased in both groups. No significant differences in $\Delta$ leptin were seen between RA $(0.21 \mathrm{ng} / \mathrm{ml})$ and controls $(0.18 \mathrm{ng} / \mathrm{ml} ; \mathrm{p}=0.37)$. On the other hand, adiponectin was significantly decreased in controls $(-3.3$ $\mu \mathrm{g} / \mathrm{ml})$ compared to RA $(-1.8 \mu \mathrm{g} / \mathrm{ml} ; \mathrm{p}=0.01)$. Negative correlations between $\Delta$ leptin and $\Delta$ adiponectin were detected in the RA group $(r=-0.29, p<0.01)$. The correlation between adiponectin and DAS28ESR was positive both at baseline $(r=0.22, p=0.01)$ and after 3 years $(r=0.18, p=0.01)$. However, no such tendencies were seen for leptin. Table 1 shows details of the correlations with changes in adipocytokine. In terms of the relationship with $\triangle \mathrm{DAS28ESR}$, no correlation was seen with $\Delta$ leptin $(r=0.07, p=0.31)$ or $\Delta$ adiponectin $(r=-0.01, p=0.91)$. Changes in lipid metabolic markers and fat percentages were detected as predictive factors for $\Delta$ adipocytokines.

Table 1. Correlations with changes in adipocytokine by univariate analysis

\begin{tabular}{|c|c|c|}
\hline & $\mathrm{R}$ & $P$ \\
\hline \multicolumn{3}{|l|}{$\Delta$ Adiponectin } \\
\hline Baseline age & -0.199 & 0.006 \\
\hline$\Delta$ High-density lipoprotein & 0.265 & 0.001 \\
\hline$\Delta$ Fat percentage & -0.144 & 0.046 \\
\hline$\triangle \mathrm{DAS} 28 \mathrm{ESR}$ & -0.009 & 0.906 \\
\hline \multicolumn{3}{|l|}{$\Delta$ Leptin } \\
\hline Baseline age & 0.258 & 0.001 \\
\hline$\Delta$ Low-density lipoprotein & 0.347 & 0.001 \\
\hline$\Delta$ fat percentage & 0.554 & 0.001 \\
\hline Fall & -0.145 & 0.045 \\
\hline$\triangle \mathrm{DAS} 28 \mathrm{ESR}$ & 0.074 & 0.311 \\
\hline
\end{tabular}

Conclusions: Leptin increased and adiponectin decreased over the course of 3 years. Correlations between $\triangle$ adipocytokines and $\triangle \mathrm{DAS} 28 \mathrm{ESR}$ were not detected. RA patients with high disease activity show higher adiponectin titers.

References:

[1] Benoist C., Mathis D. Mast cell in autoimmune disease. Nature. 2002; 420: 875-8.

[2] Cho H., Lin J., Chen W., et al. Baseline adiponectin and leptin levels in predicting an increased risk of disease activity in rheumatoid arthritis: a metaanalysis and systematic review. Autoimmunity. 2016; 49: 547-53.

Disclosure of Interest: None declared

DOI: 10.1136/annrheumdis-2017-eular.2833

\section{FRI0157 FERTILITY IN WOMEN WITH RHEUMATOID ARTHRITIS COMPARED TO HEALTHY CONTROLS}

M.E.B. Clowse, G. McDaniel, A.M. Eudy. Rheumatology, Duke University Medical Center, Durham, United States

Background: Data suggest infertility is increased in women with rheumatoid arthritis (RA) compared to healthy women. Therefore, it is possible that diminished ovarian reserve and ovulatory dysfunction may be more common among women with RA.

Objectives: To compare differences in ovarian reserve and ovulatory frequency, as well as in self-reported infertility, between women with and without RA.

Methods: Women with RA aged $20-40$ seen in a university clinic without a history of ovarian surgery or prior exposure to possible ovary-toxic medications were invited to participate in a cross-sectional survey. Healthy controls were women aged 20-40 without an autoimmune disease, matched for age and current use of hormonal contraceptives. Infertility was defined as a patient reporting physician-diagnosed infertility or being unable to get pregnant after 12 months of trying. Ovarian reserve was assessed by measuring anti-Müllerian hormone $(\mathrm{AMH})$. In women who were not taking hormonal contraceptives, progesterone level was measured from a serum sample drawn between days 21 and 23 of the menstrual cycle. Anovulation was defined as a progesterone level $<3 \mathrm{ng} / \mathrm{mL}$. In 